Review

\title{
Changes in Upper Airway Dimensions Following Orthodontic Treatment of Skeletal Class II Malocclusion with Twin Block Appliance: A Systematic Review
}

\author{
Roshan Noor Mohamed' (D), Sakeenabi Basha² (D), Yousef Al-Thomali ${ }^{(1)}$
}

'Department of Pedodontics, Taif University School of Dentistry, Taif, Saudi Arabia

2Department of Preventive and Community Dentistry, Taif University School of Dentistry, Taif, Saudi Arabia

3Department of Orthodontics, Taif University School of Dentistry, Taif, Saudi Arabia

Cite this article as: Mohamed RN, Basha S, Al-Thomali Y. Changes in Upper Airway Dimensions Following Orthodontic Treatment of Skeletal Class II Malocclusion with Twin Block Appliance: A Systematic Review. Turk J Orthod 2020; 33(1): 59-64.

\section{ABSTRACT}

Objective: This systematic review intends to evaluate the dimensional changes in upper airway dimensions (UAD) of the respiratory tract subsequent to orthodontic treatment of skeletal Class II malocclusion with Twin Block Appliance (TBA).

Methods: The quality of reporting systematic reviews and meta-analyses was decided by the PRISMA standards with PROSPERO registration number CRD42017060317. The systematic search included EMBASE, MEDLINE, Psych INFO, Scopus, CINAHL, and other reference journals and review articles. The article search was performed from March 2017 until November 2017. Cochrane's risk of bias in non-randomized studies - of interventions (ROBINS-I) was used to grade the methodological quality of the included studies.

Results: The screening procedure identified 302 studies, among which seven studies satisfied the inclusion criteria for eligibility. The UAD at the pretreatment time varied from $7.2 \mathrm{~mm}$ to $41.9 \mathrm{~mm}$ with a mean of $14.16 \mathrm{~mm}$. The post-treatment change in UAD ranged from $8.2 \mathrm{~mm}$ to $43.7 \mathrm{~mm}$ with a mean of $15.6 \mathrm{~mm}$.

Conclusion: There was a significant increase in UAD following the TBA treatment in the patient group as compared to the control group.

Keywords: Systematic review, twin block appliance, upper airway, Class II malocclusion

\section{INTRODUCTION}

Class II malocclusion is one of the most commonly encountered problems in orthodontic practice and is associated with functional, esthetic, and psychological problems of varying intensities. A change in the upper airway volume due to narrowing of the airway dimensions is a commonly encountered problem in developing Class II malocclusion with a retrognathic mandible (1). The retarded mandible causes the backward displacement of the tongue and hyoid bone, which in turn leads to a reduction in the upper airway volume. Constriction of the upper airway is one of the causative factors for the development of obstructive sleep apnea (OSA) syndrome (2). A majority of patients with OSA present with skeletal Class II malocclusion with a deficient mandible. Studies have shown that the nasopharyngeal area and depth were significantly higher among individuals with normal occlusion as compared to subjects with Class II malocclusion and the oropharyngeal airway volume was directly correlated with the length of the mandible $(1,2)$.

Many treatment modalities have been developed to treat Class II malocclusion with a retrognathic mandible. Functional appliances like mandibular advancement devices, activator headgear treatment, Twin block appliances, and fixed appliances like Forsus-fixed functional appliance and fixed appliance with activator headgear were used with or without surgical correction (3-7). Studies have shown that if the skeletal Class II malocclusion 
is diagnosed at an early age, the best treatment option is the use of functional appliances, which allows the forward growth of the mandible and prevents upper airway collapse during sleep $(7,8)$. However, the functional appliance treatment requires patient cooperation in order to be effective, which is often a major problem. The Twin Block appliance (TBA) is one of the preferred removable functional appliances used in correcting retrognathic mandible in Class II malocclusion (7, 9-16). A majority of the studies showed the use of TBA increases pharyngeal airway dimensions through the forward movement of the mandible and hyoid bone (7, 9-14); few studies showed negative results $(15,17)$. Thus, the effect of TBA on upper airway dimensions (UAD) remains uncertain. Previously, two systematic reviews have been conducted to assess the changes in airway dimensions following functional appliance treatment of Class II malocclusion $(18,19)$. The evaluation of the dimensional changes in upper airway subsequent to orthodontic treatment of skeletal Class II malocclusion with TBA was the principal objective of this systematic review.

\section{METHODS}

The systematic review is constructed in accordance with Preferred Reporting Items for Systematic Reviews and Meta-Analyses (PRISMA) standards of quality for the planning, conducting, and reporting of systematic reviews and meta-analyses (20). The review did not necessitate the approval from the Institutional Review Board and is registered under PROSPERO (CRD42017060317).

\section{Questions}

The study focused on the quantitative effects of the TBA on UAD changes in Class II malocclusion. The PICO format was used to define the research questions of the present systematic review, which is as follows:

P (Population/Patients): The human subjects with skeletal Class II malocclusion treated with TBA.

I (Intervention): TBA in skeletal Class II malocclusion.

C (comparison): Subjects not received or receiving any treatment with another appliance.

O (Outcome): Changes in UADs (in mm).

\section{Study Eligibility}

Only previously published studies in the English language that investigated the changes in UAD following TBA treatment of Class II malocclusion were included in the study. The editorial letter, case report, in vitro studies, not investigating the changes in UAD subsequent to Class II malocclusion treatment with TBA, studies with syndromes, and cleft lip or palate studies were excluded from the research

\section{Study Identification}

The database search performed included Medline (PubMed, OVID Medline, and Ebsco), Cochrane library (Cochrane review, Trails), Web of Knowledge (Social science, conference abstract),
Embase (European studies, pharmacological literature, conference abstract), CINAHL (Nursing and allied health), Psyclnfo (Psychology and psychiatry), SCOPUS (Conference abstracts, scientific web pages), and ERIC (Education) for specific search strategy with focused key terms (Class II malocclusion, skeletal, occlusion, upper airway, pharyngeal airway, nasopharyngeal airway, oropharyngeal airway, volume, dimensions, changes, evaluation, Twin block appliance, Clarks twin block, TB).

The gray literature search was performed using the following databases: Google Scholar, National Library of Medicine, Social science research for thesis (EthOS, DART-Europe), Open Grey, Institutional repositories (OpenDOAR, Bielefeld Base, Lenus, RIAN, e-publications@RCSI).In addition, four key orthodontic journals (Angle Orthodontics, American Journal of Orthodontics and Dentofacial Orthopedics, Journal of Clinical Orthodontics, and European Journal of Orthodontics) were searched from their table of contents for relevant articles. The article search was performed from March 2017 until November 2017.

\section{Study Selection}

All the titles and abstracts were screened independently and duplicated to be included in the study. An intra-class correlation coefficient of 0.86 was achieved in inter-rater agreement for study inclusion. Any conflicts among the reviewers were addressed by discussion to arrive at a consensus.

\section{Risk of Bias Assessment}

Cochrane's tool of the risk of bias in ROBINS-I was used to assess the risk of bias (21). The domains used to assess the risk of bias are summarized in Table 2. The included studies were further graded for each domain as low risk, moderate risk, serious risk, and critical risk of bias using standardized criteria. The studies were comparable to a well-performed clinical randomized trial and the domain in question was considered as having a low risk of bias. The studies which could not be compared to well-performed randomized trials but were sound for a non-randomized trial within the domain were considered as having a moderate risk of bias. The studies containing some important problems were categorized under serious risk of bias. The studies which were too problematic to provide any useful evidence on the effect of the intervention or which give no information on the basis of the judgment were categorized under critical risk of bias.

\section{Data Extraction and Data Synthesis}

The data was extracted independently by two reviewers for the included studies using a data extraction sheet and any discrepancies were resolved by arriving at a consensus through discussion. The data extracted from each included study was: first author, publication year, study type, study quality, sample size, inclusion criteria, treatment type, UAD changes (before, after, and long-term treatment), statistical analysis used, and the authors' conclusion.

\section{RESULTS}

\section{Trail Flow}

Our search strategy yielded 293 articles and an additional 9 articles were identified from the review of references and journal 
Table 1. Descriptive data of included studies

\begin{tabular}{|c|c|c|c|c|c|}
\hline Author/year & Study design & Malocclusion criteria & Intervention type & Statistical analysis & Study conclusion \\
\hline Verma /2012 & $\mathrm{R}$ & $\begin{array}{l}\text { Class II division } 1 \\
\mathrm{G} 1, \mathrm{G} 2, \mathrm{G} 3, \mathrm{ANB}>4^{\circ} \\
(\mathrm{SN}+3 \mathrm{~mm})\end{array}$ & TBA & $\begin{array}{l}\text { Paired t-test and } \\
\text { One-way ANOVA }\end{array}$ & $\begin{array}{l}\text { Significant increase } \\
\text { in PAD }\end{array}$ \\
\hline Jena /2013 & $P$ & $\begin{array}{l}\text { Class II, division } 1 \\
\text { malocclusion with RM, } \\
\text { FMA }-20^{\circ} \text { to } 25^{\circ}\end{array}$ & $\begin{array}{l}\text { S - TBA } \\
\text { C-MPA }\end{array}$ & $\begin{array}{l}\text { Paired t-test and } \\
\text { One way ANOVA }\end{array}$ & $\begin{array}{l}\text { TBA more effective } \\
\text { in increasing PAD } \\
\text { compared to MPA }\end{array}$ \\
\hline Zhang / 2013 & $\mathrm{P}$ & $\begin{array}{l}\text { Skeletal Class II with RM, } \\
\text { ANB }>3^{\circ}, \text { SNB }<80^{\circ}, \\
\text { incisor over jet }>3 \mathrm{~mm}\end{array}$ & TBA & Paired t-test & $\begin{array}{l}\text { Significant increase } \\
\text { in PAD }\end{array}$ \\
\hline Ghodke/2014 & $P$ & $\begin{array}{l}\text { Skeletal Class II with RM, } \\
\text { SNB } \leq 76^{\circ}, \text { FMA }-20^{\circ} \text { to } \\
28^{\circ}\end{array}$ & $\begin{array}{l}\text { S - TBA } \\
\text { C - Minor ortho } \\
\text { treatment }\end{array}$ & Paired t-test & $\begin{array}{l}\text { Significant increase } \\
\text { in PAD following TBA }\end{array}$ \\
\hline Chand / 2017 & $\mathrm{P}$ & Skeletal Class II with RM & TBA & Paired t-test & $\begin{array}{l}\text { Significant increase } \\
\text { in PAD }\end{array}$ \\
\hline \multicolumn{6}{|c|}{$\begin{array}{l}\text { P: prospective study; R: retrospective study; S: study group; C: control group, G: growing subjects; RM: retrognathic mandible; CVM: cervical vertebral maturity; FMA: } \\
\text { frankfort mandibular plane angle; TBA: twin block appliance; MPA: mandibular protraction appliance; PAD: pharyngeal airway dimensions; PAV: pharyngeal airway } \\
\text { volume; ANOVA: analysis of variance; S: strong; M: moderate; W: weak; G1: group 1; hypo-divergent (SN-MP: }<31^{\circ} \text { ); G2: group 2, normodivergent (SN-MP: } 31^{\circ}-34^{\circ} \text { ); } \\
\text { G3: group 3, hyper-divergent (SN-MP: }>34^{\circ} \text { ) }\end{array}$} \\
\hline
\end{tabular}

Table 2. Risk of bias assessment of included studies using Cochrane's risk of bias in non-randomized studies of interventions (ROBINS-I)

\begin{tabular}{|c|c|c|c|c|c|c|c|}
\hline \multirow[b]{2}{*}{ ROBINS -I criteria } & \multicolumn{7}{|c|}{ Author } \\
\hline & Verma & Vinoth & Jena & Zhang & Ghodke & Ali & Chand \\
\hline BC & L & L & $\mathrm{L}$ & L & L & $\mathrm{L}$ & L \\
\hline $\mathrm{BCl}$ & S & $\mathrm{L}$ & $\mathrm{L}$ & $\mathrm{L}$ & L & M & L \\
\hline BDI & M & M & L & M & M & M & M \\
\hline BSR & L & $\mathrm{L}$ & $\mathrm{L}$ & L & $\mathrm{L}$ & L & L \\
\hline Overall bias & M & M & L & L & $M$ & $M$ & $M$ \\
\hline
\end{tabular}

indices. Among these, 7 articles were identified as suitable for inclusion in the present systematic review (Figure 1).

\section{Study Characteristics and Study Quality}

The data were available from the year 2012 to 2017. Out of the 7 studies included in the review, 4 were prospective studies (2 without controls and 2 without control). Three studies were retrospective studies ( 2 without controls and 1 with control) (Table 1). Five studies were graded as a moderate risk of bias and 2 studies were graded as low risk of bias (Table 2). The number of study participants ranged from 14 to 74 (total $n=274$ ), with a mean of 39.14. In all of the included studies, lateral cephalogram was used to analyze the upper airway changes. Mean active treatment duration ranged from 4 months to 14.5 months (Table 3).

\section{Changes in Upper Airway Dimension (UAD)}

The UAD at the pretreatment time varied from $7.2 \mathrm{~mm}$ to 41.9 $\mathrm{mm}$ with a mean of $14.16 \mathrm{~mm}$. The post-treatment change in UAD ranged from $8.2 \mathrm{~mm}$ to $43.7 \mathrm{~mm}$ with a mean of $15.6 \mathrm{~mm}$. All of the included studies showed a significant increase in UAD following the TBA treatment as compared to the control group (Table 4).

\section{DISCUSSION}

The use of functional appliances in the treatment of developing Class II malocclusion with retrognathic mandible can bring the mandible forward, prevent the posterior relocation of the tongue, and improve pharyngeal airway passage (8). The present systematic review was conducted to evaluate the dimensional 
Table 3. Summary of sample size, malocclusion type, extraction, retainers used, and treatment duration

\begin{tabular}{|c|c|c|c|c|c|}
\hline Author & $\begin{array}{l}\text { Sample size (male, female)/ } \\
\text { mean age in years }\end{array}$ & $\begin{array}{l}\text { Reliability } \\
\text { measurement }\end{array}$ & $\begin{array}{l}\text { Measurement } \\
\text { technique }\end{array}$ & $\begin{array}{l}\text { Upper Airway } \\
\text { measurement }\end{array}$ & $\begin{array}{l}\text { Mean active } \\
\text { treatment duration }\end{array}$ \\
\hline Verma & $40(18,22) / 11.4$ & $\begin{array}{l}12 \text { radiographs at } \\
15 \text { day interval }\end{array}$ & Cephalometric & $\begin{array}{l}\text { Posterior outline of } \\
\text { soft palate to PPW }\end{array}$ & NA \\
\hline Jena & $\begin{array}{l}S-21(11,10) / 11.3 \\
C-16(9,7) / 12.8\end{array}$ & NA & Cephalometric & NA & $\mathrm{S}-9.3 \mathrm{~m}, \mathrm{C}-6.1 \mathrm{~m}$ \\
\hline Ghodke & $\begin{array}{l}S-20(11,9) / 10.9 \\
C-18(9,9) / 10.9\end{array}$ & $\begin{array}{l}10 \% \text { randomly } \\
\text { selected radiographs } \\
\text { at } 15 \text { day interval }\end{array}$ & Cephalometric & NA & $\begin{array}{l}S-8.2 m \\
C-7.3 m\end{array}$ \\
\hline Ali & $\begin{array}{l}S-42(21,21) / 10.4 \\
C-32(16,16) / 10.1\end{array}$ & $\begin{array}{l}30 \text { radiographs at } \\
1 \text { month interval, ANB } \\
>4 \mathrm{~mm}\end{array}$ & Cephalometric & $\begin{array}{l}\text { Perpendicular line } \\
\text { dropped on S-Ba } \\
\text { from PNS. }\end{array}$ & $\begin{array}{l}\text { S- } 8.1 \mathrm{~m} \\
\text { followed-fixed } \\
\text { therapy, } 28.3 \mathrm{~m} \\
\mathrm{C}-3 \mathrm{~m}\end{array}$ \\
\hline
\end{tabular}

\begin{tabular}{|c|c|c|c|c|c|c|}
\hline Author & & $\begin{array}{l}\text { T1 UAD mm } \\
\text { mean (SD) }\end{array}$ & $\begin{array}{l}\text { T2 UAD mm } \\
\text { mean (SD) }\end{array}$ & $\begin{array}{l}\text { T3 UAD mm } \\
\text { mean (SD) }\end{array}$ & $\begin{array}{c}\text { T2-T1 } \\
\mathrm{mm} \text { (SD) }\end{array}$ & $\begin{array}{c}\text { T3-T1 } \\
\text { mm (SD) }\end{array}$ \\
\hline \multirow[t]{3}{*}{ Verma } & G1 & $12.4(2.4)$ & $13.6(2.3)$ & NA & $1.3(2.3)^{*}$ & NA \\
\hline & $\mathrm{G} 2$ & $12.1(3.5)$ & $13.2(3.0)$ & NA & $1.3(1.3)^{*}$ & NA \\
\hline & G3 & 10.5 (1.4) & $12.0(1.8)$ & NA & $1.4(0.9)^{*}$ & NA \\
\hline \multirow[t]{2}{*}{ Jena } & $S$ & $7.2(2.04)$ & $9.4(2.7)^{*}$ & NA & NA & NA \\
\hline & $C$ & 7.7 (3.6) & $8.6(3.7)$ & NA & NA & NA \\
\hline Zhang & & $8.7(1.8)$ & $12.4(2.3)^{* *}$ & NA & NA & NA \\
\hline \multirow[t]{2}{*}{ Ghodke } & $S$ & $9.1(2.03)$ & $10.7(2.4)^{* * *}$ & NA & NA & NA \\
\hline & $C$ & $7.8(2.1)$ & $8.7(1.8)$ & NA & NA & NA \\
\hline \multirow[t]{2}{*}{ Ali } & $S$ & $32.9(4.5)$ & $33.8(4.2)^{*}$ & 35.5 (4.6) & 0.69 & $2.6(1.5)^{*}$ \\
\hline & $C$ & $41.9(4.5)$ & $43.7(4.4)$ & NA & NA & $1.8(1.9)$ \\
\hline Chand & & $7.6(0.7)$ & $8.2(0.8)^{*}$ & NA & $0.6(0.5)$ & NA \\
\hline Vinoth & & 12.02 & $13.1^{*}$ & NA & 1.08 & NA \\
\hline
\end{tabular}

changes in upper airway following orthodontic treatment of skeletal Class II malocclusion with TBA.

Inclusion Criteria: In the present study, individuals with Class II skeletal malocclusion were included because the degree of displacement of hyoid bone (superiorly and posteriorly) was greater in Class II malocclusion as compared to Class I. TBA is most commonly used in these malocclusions to increase the UAD by causing functional mandibular displacement (10-13). The present systematic review is done in accordance with PRISMA standards (20) because they are associated with better reporting of included study quality with a better assessment of bias within and across the studies included in the present review.
Changes in Upper Airway Dimension: All the included studies showed a significant increase in UAD following the TBA treatment as compared to the controls. The expansion of the maxillary arch, along with the forward growth of mandible leads to forward relocation of the tongue, thereby increasing the posterior tongue space $(7,10-13,15,16)$. The study by Verma et al. (13) showed a significant increase in UAD among individuals with skeletal Class II malocclusion following treatment with TBA. However, there were no significant changes in the lower pharynx. This may be attributed to the fact that TBA causes mandibular advancement and forward positioning of the tongue, which in turn relieves the pressure on the soft palate, thus leading to an increase in upper oropharyngeal dimension and improved airway permeability. The growth of oropharyngeal muscles caused by forward move- 


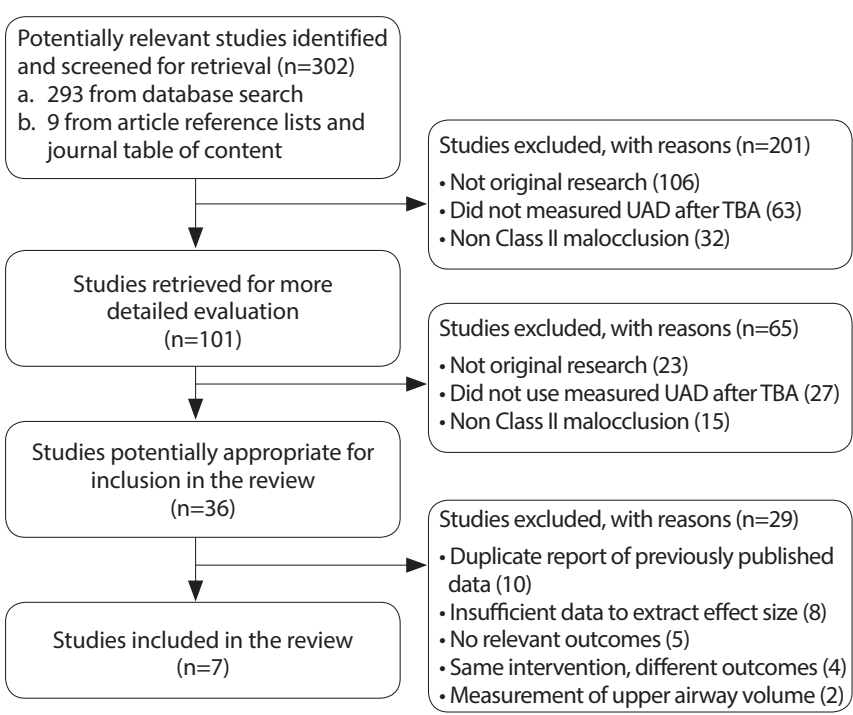

Figure 1. Flow diagram showing the subject selection of the systematic review

ment of the mandible increases UAD. Studies (1-4) have shown a positive correlation between upper airway space and the length of the mandible. Retrognathic mandible results in the reduction in UAD by causing the tongue to be positioned posteriorly. TBAs are constructed in a protrusive bite that effectively modifies the occlusal inclined plane, which causes forward growth of the mandible and in turn increases $\operatorname{UAD}(9,14)$.

Method of measurement of airway dimensions: All the studies which measured the UAD used the two-dimensional lateral cephalograms $(7,10-13,15,16)$. The main limitation with lateral cephalogram is that it cannot reveal changes in the transverse dimension but the alternative of CBCT imaging is associated with high radiation dose $(9,14,22,23)$. As the area measurements of the pharyngeal airway correlate more closely with linear measurements than that of the three-dimensional measurements, the conventional lateral cephalogram still remains a reliable diagnostic tool for monitoring the pharyngeal dimensions when utilizing area measurements.

This systematic review presented with a limitation; a meta-analysis could not be performed because there was heterogeneity across the studies. Heterogeneity results from differences in race and variations in growth patterns, which act as confounders and controls in case of ethical limitations. The construction of forest plots or funnel plots was not appropriate for the included studies. A simple descriptive and stratified comparison was able to be reported due to the disparate nature of the studies.

\section{CONCLUSION}

From the results of the explicitly selected studies included in this systematic review, it can be concluded that the use of Twin Block appliance for the correction of Class II skeletal malocclusion resulted in significantly greater improvement in increasing the UAD from $7.2 \mathrm{~mm}$ to $41.9 \mathrm{~mm}$ with a mean of $14.16 \mathrm{~mm}$ at pretreatment time to $8.2 \mathrm{~mm}$ to $43.7 \mathrm{~mm}$ with a mean of 15.6 $\mathrm{mm}$ at post-treatment time as compared to the controls.

Peer-review: Externally peer-reviewed.

Author Contributions: Supervision - R.N.M, S.B, Y.A.T.; Design - R.N.M, S.B, Y.A.T.; Supervision - R.N.M, S.B.; Resources - R.N.M, S.B, Y.A.T.; Materials - R.N.M, S.B, Y.A.T.; Data Collection and/or Processing - R.N.M, S.B, Y.A.T.; Analysis and/or Interpretation - R.N.M, S.B.; Literature Search - R.N.M, S.B.; Writing Manuscript - R.N.M, S.B, Y.A.T.; Critical Review - R.N.M, S.B, Y.A.T.

Conflict of Interest: The authors have no conflict of interest to declare.

Financial Disclosure: The authors declared that this study has received no financial support.

\section{REFERENCES}

1. Indriksone I, Jakobsone G. The upper airway dimensions in different sagittal craniofacial patterns: a systematic review. Stomatologija 2014;16:109-17.

2. Katyal V, Pamula Y, Martin AJ, Daynes CN, Kennedy JD, Sampson WJ. Craniofacial and upper airway morphology in pediatric sleep-disordered breathing: Systematic review and meta-analysis. Am J Orthod Dentofacial Orthop 2013;143:20-30. [CrossRef]

3. Buck LM, Dalci O, Darendeliler MA, Papageorgiou SN, Papadopoulou AK. Volumetric upper airway changes after rapid maxillary expansion: a systematic review and meta-analysis. Eur J Orthod 2017; 39: 463-73. [CrossRef]

4. Mattos CT, Vilani GN, Sant'Anna EF, Ruellas AC, Maia LC. Effects of orthognathic surgery on oropharyngeal airway: a meta-analysis. Int J Oral Maxillofac Surg 2011; 40: 1347-56. [CrossRef]

5. Hanggi MP, Teuscher UM, Roos M, Peltomaki TA. Long-term changes in pharyngeal airway dimensions following activator-headgear and fixed appliance treatment. Eur J Orthod 2008; 30: 598-605. [CrossRef]

6. Temani $P$, Jain $P$, Rathee $P$, Temani R. Volumetric changes in pharyngeal airway in Class II division 1 patients treated with Forsus fixed functional appliance: A three- dimensional cone beam computed tomography study. Contemp Clin Dent 2016; 7: 31-5. [CrossRef]

7. Ghodke S, Utreja AK, Singh SP, Jena AK. Effects of twin-block appliance on the anatomy of pharyngeal airway passage (PAP) in class II malocclusion subjects. Prog Orthod 2014; 15: 68. doi: 10.1186/ s40510-014-0068-3. [CrossRef]

8. Xiang M, Hu B, Liu Y, Sun J, Song J. Changes in airway dimensions following functional appliances in growing patients with skeletal class II malocclusion: A systematic review and meta-analysis. Int J Pediatr Otorhinolaryngol 2017 ;97: 170-80. [CrossRef]

9. Li L, Liu H, Cheng H, Han Y, Wang C, Chen Y, et al. CBCT evaluation of the upper airway morphological changes in growing patients of class II division 1 malocclusion with mandibular retrusion using twin block appliance: a comparative research. PLoS One 2014; 9: doi: 10.1371/journal.pone.0094378. eCollection 2014. [CrossRef]

10. Jena AK, Singh SP, Utreja AK. Effectiveness of twin-block and Mandibular Protraction Appliance-IV in the improvement of pharyngeal airway passage dimensions in Class II malocclusion subjects with a retrognathic mandible. Angle Orthod 2013; 83: 728-34. [CrossRef]

11. Ali B, Shaikh A, Fida M. Effect of Clark's twin-block appliance (CTB) and non-extraction fixed mechano-therapy on the pharyngeal dimensions of growing children. Dental Press J Orthod 2015; 20: 82-8. [CrossRef]

12. Vinoth SK, Thomas AV, Nethravathy R. Cephalomteric changes in airway dimensions with twin block therapy in growing Class II patients. J Pharm Bioallied Sci 2013; 5(Suppl 1): S25-9. [CrossRef] 
13. Verma G, Tandon P, Nagar A, Singh GP, Singh A. Cephalometric evaluation of hyoid bone position and pharyngeal spaces following treatment with Twin block appliance. J Orthod Sci 2012; 1: 77-82. [CrossRef]

14. Elfeky Hy, Fayed MMS. Three-dimensional effects of twin block therapy on pharyngeal airway parameters in Class II malocclusion patients. J World Federation of Orthod 2015; 4: 114-9. [CrossRef]

15. Chand K, Jacob S, Charles A. Assesment of changes in the sagittal pharyngeal airway dimensions post twin block therapy using polar planimeter. J Res in Dent Sci 2017; 3: 51-7.

16. Zhang $\mathrm{C}, \mathrm{He} \mathrm{H}, \mathrm{Ngan} \mathrm{P}$. Effects of twin block appliance on obstructive sleep apnea in children: a preliminary study. Sleep Breath 2013; 17: 1309-14. [CrossRef]

17. O'Brien K, Wright J, Conboy F, Sanjie Y, Mandall N, Chadwick S, et al. Effectiveness of early orthodontic treatment with the Twin-block appliance: A multicenter, randomized, controlled trial. Part 1: Dental and skeletal effects. Am J Orthod Dentofacial Orthop 2003; 124: 234-43. [CrossRef]

18. Kannan A, Sathyanarayana HP, Padmanabhan S. Effect of functional appliances on the airway dimensions in patients with skeletal class
II malocclusion: A systematic review. J Orthod Sci 2017; 6: 54-64. [CrossRef]

19. Xiang M, Hu B, Liu Y, Sun J, Song J. Changes in airway dimensions following functional appliances in growing patients with skeletal class II malocclusion: A systematic review and meta-analysis. Int J Pediatr Otorhinolaryngol 2017; 97: 170-80. [CrossRef]

20. Moher D, Liberati A, Tetzlaff J, Altman DG, PRISMA Group. Preferred reporting items for systematic reviews and meta-analyses: the PRISMA statement. J Clin Epidemiol 2009; 62: 1006-12. [CrossRef]

21. Sterne JA, Hernan MA, Reeves BC, Savovic J, Berkman ND, Viswanathan $\mathrm{M}$, et al. ROBINS-I: a tool for assessing risk of bias in non-randomised studies of interventions. BMJ 2016; 355: doi: 10.1136/bmj. i4919. [CrossRef]

22. Aboudara C, Nielsen I, Huang JC, Maki K, Miller AJ, Hatcher D. Comparison of airway space with conventional lateral headfilms and 3-dimensional reconstruction from cone-beam computed tomography. Am J Orthod Dentofacial Orthop 2009; 135: 468-79. [CrossRef]

23. Aboudara CA, Hatcher D, Nielsen IL, Miller A. A three-dimensional evaluation of the upper airway in adolescents. Orthod Craniofac Res 2003;6 (Suppl 1): 173-5. [CrossRef] 